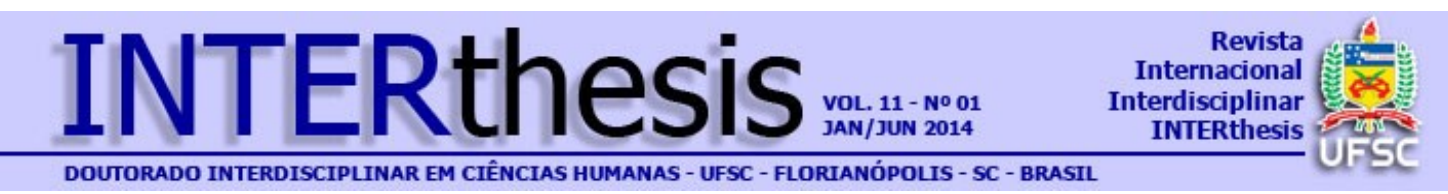

\title{
UMA ÉTICA AMBIENTAL: A PARTIR DA NATUREZA COMO UM MOVIMENTO VITAL
}

\section{Resumo:}

\author{
Doris Gomes ${ }^{1}$ \\ Sônia Terezinha Felipe ${ }^{2}$
}

Uma seleção de artigos da bioética ambiental contemporânea produziu algumas perguntas e debates sobre a ética biocêntrica. Desenvolvem-se dois eixos de análise: o primeiro que mostra a relação entre o agente moral e o paciente, com a universalização das máximas morais, incluindo todos os seres vivos, racionais e não racionais, na considerabilidade moral. Os seres vivos são inter-relacionados e precisam um do outro, mas somente os seres humanos são capazes de julgamentos morais e, portanto, podem ser considerados como agentes morais, embora ele deve ser considerado moral do ponto de vista do paciente. O segundo eixo aborda o interesse na manutenção da vida, que engloba esta relação de reciprocidade, onde matar outro ser vivo pode se tornar um problema operacional de sobrevivência natural, quer certo ou errado, e os valores naturais e humanos são inseridos nestas preocupações. Podemos concluir que a luta para preservar o ambiente e o respeito pela natureza devem caminhar de mãos dadas com a possibilidade de emancipação social da humanidade. A construção de um novo agente moral também envolve a construção de uma nova vida social, que é onde o benefício está - no centro do pensamento filosófico e nas atitudes do agente moral.

Palavras-chave: Ética. Ética biocêntrica. Bioética ambiental. Considerabilidade moral. Agente moral.

\section{INTRODUÇÃO}

Nas últimas décadas, a relevância entre custo e benefício das tecnologias e modo de vida no mundo moderno, com a ameaça cotidiana da extinção de espécies - animais e vegetais -, se eleva a preocupação com a sobrevida da própria espécie humana. $O$ debate em torno do meio ambiente adquire preocupação de proporções

\footnotetext{
${ }^{1}$ Doutora em Enfermagem pela Universidade Federal de Santa Catarina. Desenvolve trabalho e docência na área de Saúde Coletiva, Bioética e Ética e Legislação, Florianópolis, SC, Brasil. E-mail: dorisgomes@bol.com.br

${ }^{2}$ Doutora em Filosofia pela Universität Konstanz, Alemanha. Professora Associada II da Universidade Federal de Santa Catarina, aposentada, atuando na orientação de teses e dissertações, e coordenando projetos de investigação e de extensão, Florianópolis, SC, Brasil. E-mail: felipe@cfh.ufsc.br
}

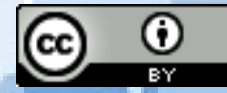

Esta obra foi licenciada com uma Licença Creative Commons - Atribuição 3.0 Não Adaptada. 
alarmantes para uma gama cada vez maior de estudiosos e pensadores. A própria relação entre países com alto grau de desenvolvimento, que, de certa forma, têm muito pouco a preservar de natureza intocada e os chamados países em desenvolvimento, com uma natureza ainda abundante e um considerável poder desenvolvimentista, conforma um grande problema ético na contemporaneidade: a contradição entre o que a humanidade já conseguiu produzir em termos de tecnologia, de relações sociais e a gigantesca destruição do meio ambiente do planeta. Questiona-se, então, que tipo de desenvolvimento humano e de relações entre os seres vivos a história humana deveria seguir construindo.

As grandes tradições filosóficas se apoiam em três vertentes antropocêntricas para fundamentar a ideia de superioridade do ser humano sobre outras espécies:

1. A tradição judaico-cristã, que situa o homem na grande cadeia de seres, num patamar logo abaixo de Deus e dos anjos e acima de todos os outros seres vivos. Assim o ser humano aparece como um semideus feito à "Sua" imagem e semelhança;

2. O dualismo cartesiano, que considera o homem superior a outros seres vivos por um componente diferenciado: a alma. Os animais, por não possuírem esse componente divino, são considerados apenas seres autômatos e passíveis de inferioridade; e

3. O ponto de vista helênico, que diferencia valorativamente o ser humano em função da sua essência racional. Uma visão que se encontra profundamente enraizada no pensamento filosófico moderno. Esse paradigma, representado especialmente por Kant e Hume, se baseia no egoísmo ético para uma abordagem humanística de valor e obrigação. Assume como desafio filosófico "uma generalização epistemológica e motivacional da natureza do agente, baseada no auto-interesse" (GOODPASTER, 1998, p. 57).

Seguindo o caminho da valorização moral dos seres vivos a partir da vida como o centro da consideração e valoração moral, as teses de alguns pensadores na atualidade se diferenciam das diversas teorias antropocêntricas de consideração moral, válidas somente para os seres racionais. Paul Taylor, Tom Regan e Kenneth Goodpaster são pensadores que aprofundam o debate em torno dos diferentes papéis dos seres humanos como agentes morais e dos outros seres considerados pacientes morais, estabelecendo possíveis relações entre eles.

R. Inter. Interdisc. INTERthesis, Florianópolis, v.11, n.1, p. 213-230, Jan./Jun. 2014 
Kenet Goodpaster é um dos primeiros autores a abrir caminhos para a construção de uma proposição que amplia a possibilidade de considerabilidade moral sob o prisma da valorização intrínseca da vida. Contrapondo-se às teorias filosóficas antropocêntricas, procura alargar ainda mais o potencial de valorização dos seres vivos. Faz uma crítica à filosofia moral moderna que tem como perspectiva humanística de valor e obrigação, o egoísmo ético. Pressupõe um pensamento diferenciado das abordagens éticas kantianas e humeanas, em que o ponto de vista do desafio filosófico da natureza motivacional do agente se baseia no auto-interesse. Debate um novo paradigma para abrir caminhos além de uma visão individual das pessoas, suas alegrias ou tristezas, construindo a perspectiva de uma possível universalização ética para além dos seres vivos racionais. O autor promove um debate com foco na força das atribuições de "direitos" em contextos comparativos, em que é pressuposta como crucial uma questão de força e/ou prioridade na considerabilidade moral.

Goodpaster critica uma visão mais estreita de comunidade moral como a defendida por Frankena e Feinberg - que propõe a ampliação da considerabilidade moral somente aos seres sencientes (seres que sentem e tem algum nível de consciência). Especificando diferenciações entre direitos morais e considerabilidade moral, procura abraçar, também na comunidade moral, os seres vivos não sencientes. Refere-se ao "interesse em manter-se vivo" como uma necessidade que foge tanto de uma visão hedonista de ser senciente, quanto de uma visão de continuidade entre coisas vivas e não vivas.

O autor parte do pressuposto de que coisas inanimadas não têm um interesse inerente a elas mesmas, pelo bem ou pelo mal. Assim, uma planta necessita da terra, tem carência do sol e da chuva, e luta através de suas possibilidades para sobreviver, mas a terra mesmo esgotando o seu potencial mineral, não pode reclamar a vida. Afirma, então: "nenhum encurtamento de condições para ser vivo parece-me ser um critério plausível e não arbitrário" (GOODPASTER, 1998, p. 58).

Para Paul Taylor e Tom Regan, a valorização moral tem como causa essencial o bem ou valor inerente da vida, em seu direito próprio. Tom Regan defende a concepção de uma ética ambiental, que comporte a existência de seres não humanos com posição moral e a formação de uma comunidade moral composta por todos os seres conscientes e alguns seres não-conscientes. Então, o R. Inter. Interdisc. INTERthesis, Florianópolis, v.11, n.1, p. 213-230, Jan./Jun. 2014 
pressuposto para uma ética genuinamente ambiental exige que seja reconhecida a legitimidade moral de não-humanos. Essa ética deve reconhecer que "objetos naturais não conscientes têm um bem ou um valor seu próprio, independente de interesses humanos" (REGAN, 1981, p. 30).

Paul Taylor, igualmente, defende uma ética ambiental centrada na vida, em que os seres humanos estão moralmente vinculados em sua defesa a partir de "obrigações morais prima fácie a plantas selvagens e animais, eles mesmos, percebidos como membros da comunidade biótica da terra" (TAYLOR, 1998, p. 72). Estes autores que consideram a vida como bem inerente e ressaltam o princípio da preservação como prima facie do dever, acreditam que "o inimigo comum de todos os preservacionistas é aquele que aceita o princípio dos interesses humanos" (REGAN, 1981, p. 32).

Entretanto, ao separarem em definitivo os interesses humanos do interesse na manutenção da vida dos outros animais e seres vivos, talvez tenham deixado uma lacuna a ser debatida. Segundo os autores, o ser humano por sua razão, deveria ser isolado da natureza para o benefício desta e desconsiderado como ser capaz de um convívio saudável com o meio circundante. Talvez, movidos pela defesa, mais do que necessária, do meio ambiente das atrocidades destrutivas perpetradas pelas sociedades humanas até os dias atuais, eles sejam levados a fazer um paralelo com a teoria kantiana da moralidade e, assim, separam formalmente o racional do natural (empírico), na busca do caminho que levaria a uma pureza moral.

Comparar o bem inerente do caribu (animal das regiões áridas, forma norteamericana da rena) com o bem não inerente dos benefícios econômicos, realmente nos leva a grandezas incomensuráveis e, portanto, a uma relação de intransigência valorativa. Mas, se a vida humana entra nesse jogo, seu benefício ou sua viabilidade, as grandezas podem, dialético-dialogicamente, ser conflitadas. E é esse o tipo de conflito que nenhuma teoria ética da natureza pode fugir ou relegar ao segundo plano. Deve ser inserida nesse debate, a contradição entre a relação dos valores inerentes na luta pela manutenção da vida, com a implacabilidade da morte (a morte como um estado inerente à própria vida) e as relações sócio/ambientais que levam a este tipo de conflito.

R. Inter. Interdisc. INTERthesis, Florianópolis, v.11, n.1, p. 213-230, Jan./Jun. 2014
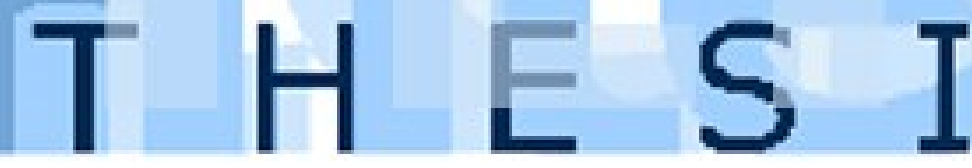
Aponta-se para ponderação: como relacionar os valores, grande parte das vezes conflitantes, que podem pesar em um julgamento moral? Como incluir na pauta das sociedades humanas modernas um pensamento universal biocentrado, sem transformações no próprio ser humano sob o ponto de vista individual e coletivo/social?

\section{A CONCEITUALIZAÇÃO DE VALORES DE PAUL TAYLOR E TOM REGAN}

A perspectiva biocêntrica da natureza sugere quatro componentes conjugados para sua realização: 1 . os seres humanos considerados como membros da comunidade viva da terra; 2 . o ecossistema natural visto como uma complexa teia de elementos interligados, onde a função biológica de cada um depende da função biológica dos outros; 3 . a concepção de cada ser vivo é igualmente um centro teleológico de vida, buscando seu bem próprio, por seu próprio caminho: conscientes ou não, cada um orienta-se para a preservação das suas atividades e bem-estar; e 4. a negação da superioridade humana em relação a outras espécies, por seu valor inerente. Sem negar as diferenças evolutivas entre as espécies e as características diferenciadas dos seres humanos, as leis da genética, da seleção natural e da adaptação, juntamente com os desafios ambientais, são aplicadas a todos os seres vivos como criaturas biológicas que fazem parte de um todo e não além dele.

O ponto de vista biocêntrico defendido por Taylor concebe que as relações ecológicas entre qualquer comunidade de seres vivos e o seu ambiente formam um conjunto orgânico de partes funcionalmente interdependentes. Existe, sob esse ponto de vista, um equilíbrio ecológico como cadeias alimentares, relações predador-presa, e sucessão vegetal em uma floresta, autorregulada e equilibrada no seu conjunto "em longo prazo, a integridade de toda a biosfera do nosso planeta é essencial para a realização do bem das suas comunidades constituintes de vida, tanto de humanos como de não humanos" (TAYLOR, 1998, p. 77).

Ao invés do ser humano, ao se diferenciar socioeconômico e culturalmente de outras espécies biológicas, construindo a sua própria história, negar as diferenças entre os seres humanos e as outras espécies biológicas existentes ou desmerecer outras espécies pelo simples mérito de ser humano, deveria postular que o bem R. Inter. Interdisc. INTERthesis, Florianópolis, v.11, n.1, p. 213-230, Jan./Jun. 2014 
estar dos seres humanos depende da solidez ecológica e da saúde de muitas comunidades de plantas e animais. Entretanto, a possibilidade da absoluta exterminação da nossa própria espécie por nossas próprias mãos - como já fizemos acontecer com diversas outras espécies vivas -, leva a ética postulada por Taylor e outros autores biocêntricos a um novo enfoque valorativo da própria vida como um bem inerente: como uma necessidade à humanidade, em seu atual estágio civilizatório.

Afinal, o papel dos seres humanos como agentes morais impulsiona a tomada de decisões sobre o que fazer, sobre quais eventos no mundo são bons ou maus, desejáveis ou indesejáveis, levando em conta nessas sentenças, que o ser humano deve promover ou proteger os seres por seu próprio bem. O que, muitas vezes, não traz benefícios diretos ao agente moral, mas estabelece padrões de avaliação feitos sobre o que é favorável ou desfavorável em relação ao bem de determinada entidade, mesmo não-humana. Desta maneira, pensar numa atitude de respeito pela natureza é conceber um sistema de crenças - formal -, que reconheça a atitude de respeitar outro ser como única atitude adequada/certa, em direção a consideração de todas as formas de vida: uma atitude de respeito pelas coisas vivas possuidoras de valor inerente. Normas e padrões de conduta moral devem ser validados e vinculados a todos os agentes morais, seguindo uma teoria de ética humana de crescente respeito pelas pessoas e seres vivos de maneira geral.

Se em relação às pessoas temos um sistema de direitos "estes direitos são formas de conduta em que é dado reconhecimento público a cada pessoa como valor inerente" (TAYLOR, 1998, p. 74), da mesma forma, deveríamos construir um tipo particular de sistema de regras, para definir os deveres dos seres humanos com relação ao mundo natural, na perspectiva do paciente moral, "não creio que o referencial clássico do conceito que estrutura os direitos morais deve ser estendido par incluir seres vivos não humanos" (TAYLOR, 1998, p. 85). Assim, o valor inerente de qualquer coisa viva implicaria "desconsiderar seus méritos e deficiências, se eles são seres julgados a partir de uma perspectiva humana ou do ponto de vista de sua própria espécie" (TAYLOR, 1998, p. 81).

Paul Taylor quando analisa a origem social do conceito de graus de valor inerente, parece considerar que as sociedades modernas, ao contrário das sociedades feudais com estruturas de classe rígidas e hereditárias (nobres e R. Inter. Interdisc. INTERthesis, Florianópolis, v.11, n.1, p. 213-230, Jan./Jun. 2014 
plebeus), são baseadas numa premissa igualitária e universalista, em que as novas e não tão evidentes diferenças de classe (já não tão novas) estariam subsumidas e seriam suplantadas pelo mérito pessoal. Os seres humanos em virtude de sua humanidade teriam o mesmo valor inerente, em que deriva a crença na universalidade dos direitos humanos. Mas, Taylor considera que a maior parte das pessoas nas nossas sociedades modernas ocidentais, não mantêm na prática apesar desta pretensa igualdade de direitos garantida nas legislações e defendida pelo direito contratual - uma perspectiva igualitária na comparação dos seres humanos com outros seres vivos. Aqui, há um conflito de conceitos, quando Taylor questiona por que numa sociedade ocidental "moderna democrática", onde as pessoas seriam consideradas pelo mérito, não há na prática, uma perspectiva humanitária universal para com a natureza.

Segundo Taylor (1998, p. 84), “os seres humanos são iguais a não-humanos justamente vivendo como parte integrante de um todo unificado e as coisas vivas são funcionalmente inter-relacionadas". Podemos, a partir desta afirmação, destacar uma contradição como base na fundamentação de uma ética que se proponha igualitária e universalista, como a biocêntrica:

1. a disparidade entre o ideal dos direitos humanos e a sua concretização prática nas sociedades modernas;

2. a distância entre uma teoria ética universalista e a sua correspondente na realidade, em sociedades onde o individualismo hedonista é festejado como o verdadeiro estilo de vida pós-moderno; e

3. a diferença entre as concepções de mundo construídas sobre os conceitos de mérito pessoal e classe social, ainda relevante nos atuais modelos societários.

Essas contradições, ao mesmo tempo em que obstacularizam a essência igualitária (mesmo em direitos) do ser humano "moderno", dificultam a atribuição de valoração moral universalizável entre os próprios seres humanos e, mais ainda, entre os seres humanos e outros seres vivos. Quando a igualdade ainda permanece como um ideal utópico para a humanidade e a universalidade parte de um lugar/conceito formal, um impasse se mantém na vida moral cotidiana dos seres humanos, em suas relações sociais próprias. Os diferentes e dinâmicos contextos de disputas e conflitos de interesses constroem problemas éticos sob mediações em diferentes níveis reflexivos, onde preceitos de universalidade entram em conflito com

R. Inter. Interdisc. INTERthesis, Florianópolis, v.11, n.1, p. 213-230, Jan./Jun. 2014 
uma prática hedonista, ainda hegemônica. A alienação no trabalho, ainda persistente, associada a uma atomização das vidas e relações na contemporaneidade, não materializa o ideal humano universalista e igualitário para os próprios seres humanos.

Nesse sentido, a construção de uma ética biocentrada e pautada em características biológicas como inerentes a todos os seres vivos, entrelaçados em uma comunidade biótica, deve estar em consonância com a transformação da vida social. A ética ambiental de Paul Taylor propõe um sistema conceitual, em que o ser humano começa a olhar para outras espécies como olha a sua própria (aqui está a contradição e o conflito debatido), desenvolvendo a disposição para ver o mundo do ponto de vista do seu bem próprio e do seu próprio bem. Entretanto, se esse olhar está impregnado de uma hierarquia social, mesmo não tão nítida quanto na era monárquica, um desafio ético perpassa a necessidade de transformações sociais para o agente moral, mesmo sob o ponto de vista do paciente moral. Assim, os agentes morais como seres sociais e históricos, além de biológicos, devem pugnar por liberdade e autonomia reais, conjuntamente a atitudes de respeito pela natureza.

Taylor também vai distinguir a teoria biocêntrica de todos os outros pontos de vista antropocêntricos, pois, de acordo com ele, as ações humanas que afetam o meio ambiente natural são observadas sob dois aspectos: "elas tem consequências que são favoráveis (ou não favoráveis) ao bem-estar dos humanos, ou elas são consistentes (ou inconsistentes) como sistema de normas que protegem e implicam direitos humanos" (TAYLOR, 1998, p. 71). Assim, o ponto de vista biocêntrico parte de uma distinção clara entre valor inerente como um bem próprio e as outras formas de valoração moral, como o valor intrínseco, que estaria relacionado a um conceito de mérito ou excelência.

Desta maneira, concebe seis distinções valorativas:

1. valor instrumental ou valor de uso, que define a possibilidade de uso de um ser vivo por outro, como meio efetivo para algum fim (desde a própria sobrevivência até as necessidades culturais, como derrubar uma árvore para fazer um livro, por exemplo);

2. valor comercial, baseado no valor de troca, que seria o valor de uso acrescido do trabalho humano e transformado em uma mercadoria, mensurado no preço pelo qual esta "coisa" pode ser vendida, tendo por finalidade o lucro;

R. Inter. Interdisc. INTERthesis, Florianópolis, v.11, n.1, p. 213-230, Jan./Jun. 2014 
3. valor por mérito ou excelência, como propriedade possuída por um ser, valorizado por aplicar da melhor forma possível esta propriedade (fazer bem feito o que faz);

4. valor do bem imediato, como uma atividade exercida por seres conscientes, que sentem alegria, satisfação ou prazer em algo - um valor considerado utilitarista;

5. valor intrínseco, que seria um valor atribuído de fora, por um sistema de valores humanos. Do ponto de vista moral ele pode se constituir em um dever negativo, como não destruir, não denegrir, não vandalizar, e como dever positivo, proteger contra a destruição e o vandalismo possivelmente praticado por terceiros; e

6. valor inerente, quando algo é valorizado simplesmente pelo fato de ter um bem em si, um bem próprio. A classe de entidades que tem valor inerente é estendida a todos os seres vivos, no sentido da manutenção da vida e do próprio bem-estar. Segundo Regan (1981, p. 30), "a presença de valor inerente de um objeto natural é independente de alguma consciência, interesse, ou apreciação sobre algum ser consciente". Aponta que seria um absurdo lógico graduar valor inerente para auferir superioridade ao ser humano em detrimento dos outros seres vivos.

Regan e Taylor defendem que o valor inerente de um objeto natural vai em direção a uma atitude de admiração respeitosa. Liga o que é inerente na natureza como um ideal da natureza humana e dá origem ao princípio da preservação (deixar-estar): não-destruição, não-interferência, não-intromissão. O respeito é adequado, por que é uma atitude em direção ao valor em si mesmo. A preservação, assim, torna-se um princípio (prima facie) que deve ser considerado como um imperativo moral. Taylor deixa claro nos artigos analisados que é no tratamento dos organismos selvagens dentro de um ecossistema isolado, que o conceito de "ter um bem próprio" é por ele aplicado. Apesar de se questionar como iriam se inserir os indígenas ou os extrativistas nessa relação valorativa poder-se-ia afirmar que a teoria do valor inerente é importante para a manutenção dos ecossistemas fechados, ainda existentes no planeta. Entretanto, o valor inerente talvez não seja suficiente para resolver as principais contradições e conflitos de interesse, presentes nos julgamentos morais entre os seres vivos.

R. Inter. Interdisc. INTERthesis, Florianópolis, v.11, n.1, p. 213-230, Jan./Jun. 2014
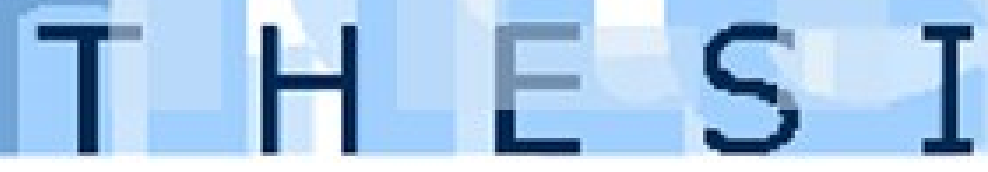


\section{GOODPASTER E A CONSIDERABILIDADE MORAL}

Goodpaster (1998) inicia o debate biocêntrico assumindo a necessidade de uma melhor compreensão da amplitude do respeito moral, que tipo de entidades devem receber atenção moral, bem como, a natureza do bem que se supõe promovido pela moralidade. Considera que há algo emergencialmente acrítico nas abordagens morais do egoísmo ético numa perspectiva humano centrada, e que o desafio filosófico da ética biocêntrica seria fugir de avaliações epistemológicas baseadas no auto-interesse do agente moral (como as abordagens éticas kantianas e humeanas). Desta maneira, a simples condição de ser vivo como entidade e sistema de entidades, que até agora eram inimagináveis como "reivindicadores" da atenção moral do ser humano - o próprio biossistema -, estimula um movimento ético de rompimento de paradigmas "para além do humanismo".

O autor começa a construir sua argumentação considerando o pensamento consequencialista de quatro filósofos contemporâneos, que ampliam a considerabilidade moral para além do humano: Warnock, Frankena, Singer e Feinberg. A crítica que Warnock faz ao princípio da moral kantiana, onde a considerabilidade humana se faz nos limites da razão ou de sua potencialidade (incluídas crianças e pessoas mentalmente debilitadas), modifica a ideia sobre o objeto da moralidade para ampliar a possibilidade de inclusão de não humanos. Nessa perspectiva, o critério da considerabilidade moral é "localizado na capacidade de sofrer dor" ou experimentar prazer/felicidade (GOODPASTER, 1998, p. 61).

A partir dessa crítica inicial, se abre o leque da considerabilidade moral para seres não-humanos. Frankena é outro autor que concorda com esta argumentação. Peter Singer vai acentuar que o limite da senciência é a única fronteira defensável na preocupação com os interesses dos outros. Assim, Warnock, Frankena e Singer apontam claramente para a senciência como delimitadora de considerabilidade moral. Já a tese defendida por Feinberg acrescenta que uma visão ampliada de direitos deve englobar seres que têm interesse, seguindo o pressuposto de que um ser sem interesses é um ser incapaz de ser maltratado ou beneficiado.

Entretanto, Feinberg continua considerando que interesse pré-supõe logicamente, capacidades psicológicas por desejos, quereres ou objetivos, possibilidades não estendidas às plantas e outros tipos de seres não-sencientes.

R. Inter. Interdisc. INTERthesis, Florianópolis, v.11, n.1, p. 213-230, Jan./Jun. 2014
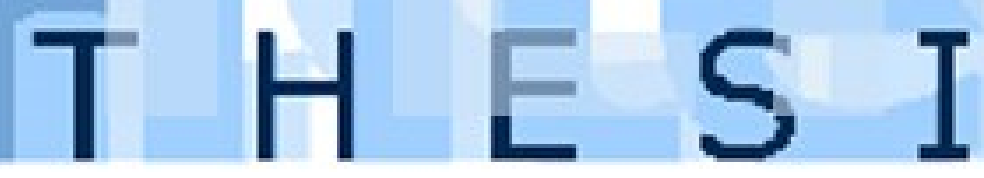
Parece estarem implícitos dois argumentos nessa construção: 1. apenas seres que podem ser representados merecem consideração moral; e 2. apenas seres capazes de serem beneficiários merecem consideração moral. Neste raciocínio, não teríamos ultrapassado a própria concepção do bem hedonista, pois o beneficiário é restrito a seres que são capazes de prazer e dor ou de interesse num sentido restrito.

Goodpaster (1998) vai procurar se posicionar de maneira muito mais crítica, introduzindo no debate com esses pontos de vista o argumento de que as capacidades para sofrer e para o prazer/felicidade são desenvolvidas na evolução, como características adaptativas de alguns seres vivos para evitar as ameaças à vida e que, portanto, ainda estreitam a possibilidade de considerabilidade moral. Goodpaster, ao mesmo tempo em que absorve o argumento utilitarista de interesse de Feinberg para ampliação da considerabilidade moral, mesmo que estritamente concebido, dá uma nova perspectiva sobre a questão.

Ultrapassa a concepção do bem hedonista e engloba os seres nãosencientes. Mesmo não tendo capacidade para sentir dor ou prazer/felicidade, todos os seres vivos têm interesse em se manterem vivos e ações morais podem ser desenvolvidas em benefício ou malefício desse interesse. Assim, a valorização do simples interesse em manter a vida serve como argumento para ampliação da considerabilidade moral a todos os seres vivos.

Goodpaster defende que não há necessidade da existência de um sistema nervoso central ou de sentimentos, para qualificar um ser vivo como sendo um ser com interesses: estar vivo já seria o suficiente. Além disso, procura discutir as condições necessárias e suficientes que devem regular a consideração moral, na relação com diversas questões de relevância como status de vida (muito jovens ou idosos), na relevância (folhas das árvores, espécies de um ecossistema), entre outras.

\section{DEBATE COM AS CRÍTICAS A GOODPASTER}

Regan (1981) tece uma crítica a Goodpaster, por ele atribuir à vida condição necessária e suficiente para que algo seja moralmente considerável "limitar a classe dos seres que têm valor inerente à classe de seres vivos parece ser uma decisão arbitrária e não serve bem, como base para uma ética ambiental" (REGAN, 1981, p.

R. Inter. Interdisc. INTERthesis, Florianópolis, v.11, n.1, p. 213-230, Jan./Jun. 2014 
33). O princípio da preservação significa não interferência e não intromissão como um imperativo moral, independente da beleza (mérito) e da utilidade, a natureza pode ter um valor inerente. O utilitarismo hedonista falha na qualificação para uma ética ambiental, pois não pode discutir fora da origem dos prazeres proporcionados pelo meio ambiente, assim, um ambiente de plástico poderia dar origem a prazeres iguais aos ambientes naturais - e poderiam ser fabricados.

Hunt (1980), quando critica Goodpaster, cita os argumentos de vários bioeticistas utilitaristas contemporâneos, nomeadamente Warnock, Frankena, Singer e Feinberg, como estreitos, por considerarem moralmente, somente comunidades morais sencientes. Goodpaster deixaria, também, de fora da comunidade moral, o que considera como sendo "meras coisas". Para Hunt isto significa um estreitamento de considerabilidade moral, afirma que os argumentos como capacidade de sofrer e ser feliz atribuídos aos seres sencientes, seriam estreitos. Por que ter interesse, então, seria uma visão mais ampla? Hunt avalia que Goodpaster cai na mesma armadilha do estreitamento de visão de comunidade moral destes autores e sugere a incorporação neste campo de considerabilidade moral de todos os "seres em existência", vivos e não vivos. Hunt propõe uma visão de continuidade material entre seres vivos e não vivos, a partir de uma troca existente entre os seres animados e os inanimados, entre o mundo biológico e o mundo mineral. Então, o autor se pergunta: "onde está a justificativa para sinalizar uma demarcação ética entre os vivos e os não vivos?" (HUNT, 1980, p. 65).

No conflito gerado com o pensamento de Regan e Hunt, cada qual com seus critérios valorativos, Goodpaster acrescenta que meras coisas não podem se beneficiar de determinadas situações, pois não possuem um bem em si. Entretanto, as coisas vivas têm interesse genuíno em se manterem vivas e lutam por si mesmas, pelo benefício do princípio da vida - procurando resistir aos danos a ela -, mesmo que não possuam consciência ou sensibilidade para externar positivamente esse interesse. Desta maneira, coisas inanimadas não têm capacidades ou interesse pelo bem ou pelo mal.

Nesta perspectiva, o interesse não está ligado à capacidade de sentir dor ou prazer, mas à necessidade e carência, assim, beneficência e não-maleficência "não são apenas ingredientes necessários em nossa concepção parcelada de obrigação moral (não moral), elas são centrais" (GOODPASTER, 1980, p. 282). O interesse é

R. Inter. Interdisc. INTERthesis, Florianópolis, v.11, n.1, p. 213-230, Jan./Jun. 2014 
considerado crucial, porque o conceito de moralidade está diretamente relacionado à beneficiência ou não-maleficência - que inexistem na ausência de entidades aptas a serem beneficiadas ou prejudicadas. Coisas inanimadas podem ser consideradas maravilhosas e há pleno direito a essa consideração, mas existe uma fronteira entre a moral e, talvez, a estética - que não pode ser alicerçada na beneficência. $O$ autor aponta para algo que poderia ser chamado de consideração "quase-moral".

Mesmo que haja certa visão de continuidade entre coisas vivas e não vivas, ou mesmo que umas precisem das outras para sobrevivência (como as plantas precisam da terra para sobreviver), a considerabilidade moral se atém aos seres vivos que têm interesse - como valor intrínseco à vida - e que lutam, de alguma forma, para se manterem vivos. Não se pode fazer o bem ou evitar danos, ou seja, dar consideração moral num sentido relevante (relevância grifada pelo autor), às entidades que não têm interesse, como os objetos inanimados. Uma nova etapa parece se abrir para um pensamento ético vida-centrado, que prevê as coisas vivas em movimento e inter-relacionadas, em relações permeadas por conflitos e contradições que ensejam um julgamento moral.

\section{QUATRO DISTINÇÕES PARA UMA AMPLA REDE MORAL}

Goodpaster (1998) vai considerar quatro distinções que argumentam pela incorporação construtiva de uma ampla rede moral: a todos os seres vivos. Delineia, para tanto, um sistema de condições necessárias e suficientes para a considerabilidade moral em si, que podem ser interpretadas a partir de uma complexa teia de relações entre os seres vivos. A primeira delas se pauta na sustentação diferenciada entre direitos morais e considerabilidade moral, assim, absorve de Warnock o sentido ampliado de paciente moral, onde a noção de direito torna-se mais específica. Transfere a permissividade de consideração moral para além de seres racionais e sencientes englobando todos os seres vivos, mas sem a necessidade do estabelecimento do dever moral para todos igualmente e, também, "não apenas em razão da sua utilidade para o ser humano" (GOODPASTER, 1998, p. 58).

A segunda distinção se refere à relação entre considerabilidade moral e significância, relevância moral. Para julgamento moral comparativo em casos de

R. Inter. Interdisc. INTERthesis, Florianópolis, v.11, n.1, p. 213-230, Jan./Jun. 2014
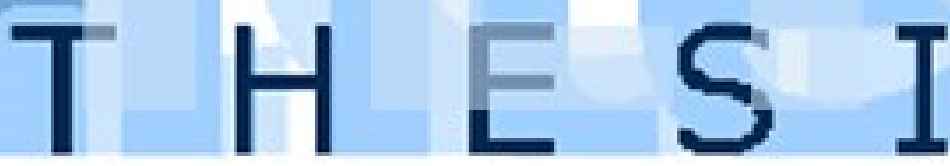
conflito, o critério de relevância moral de uma vida sobre outra se estabelece: em determinados contextos comparativos uma relação valorativa é necessária para definir maior ou menor relevância moral. $\mathrm{O}$ fato de uma árvore merecer consideração moral não está separado do questionamento se árvores merecerem mais ou menos consideração moral que cachorros. Goodpaster se pronuncia: "desconfio que a verdadeira força das atribuições de "direitos" deriva de contextos comparativos, contextos em que considerabilidade moral é pressuposto e questão de força, é crucial" (GOODPASTER, 1998, p. 59).

No debate da terceira consideração, Goodpaster contra argumenta a proposta de separação meta-moral de Feinberg, que possibilita padrões morais discriminatórios, como em outros tempos aconteceu com os negros, mulheres, crianças e outras instâncias de "interdição meta-moral". Alega que Frankena parece estar correto ao definir meta-ética como uma disciplina parcialmente normativa, por isso, esse terceiro ponto leva em conta a relação entre inteligibilidade e questões normativas, estabelecendo qual ser merece considerabilidade moral e pode, assim, ser descrito. Separa o dever do direito, normatizando (regrando) o dever em relação àqueles seres que merecem considerabilidade moral, mas sem o dever estendido ao seu domínio.

Como última distinção, sugere questões de estrutura ao invés de questões de aplicação. Identifica que os seres humanos como agentes morais, estão sujeitos aos seus próprios limites morais. A nossa limitação cognitiva - uma capacidade psicológica ou nutritiva própria - possibilita um nível operativo com limite de racionalidade: "prima facie versus direito real". Faz relação com os limites do agente moral entre o nível regulativo, o que deve ser seguido para todas as coisas vivas, e a necessidade de operacionalização, ou seja, onde ficam estabelecidos os limites da racionalidade humana.

\section{CONSIDERAÇÕES FINAIS}

Dois eixos de análise são destacados:

1. O primeiro mostra a relação entre o agente moral e o paciente moral, ou seja, ser racional e outras formas de ser vivo (biológico) não racional, com a universalização de máximas morais - tanto sob o ponto de vista de seres racionais

R. Inter. Interdisc. INTERthesis, Florianópolis, v.11, n.1, p. 213-230, Jan./Jun. 2014
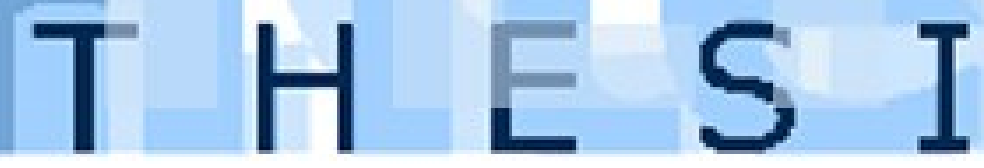
quanto sob o ponto de vista de seres vivos não racionais. Procura-se igualar todos os seres vivos em considerabilidade moral, seguindo a premissa de que os seres vivos se inter-relacionam uns com os outros, e se necessitam uns aos outros, mas somente o ser humano é capaz de julgamento moral e, portanto, pode ser considerado agente moral; e

2. O segundo eixo aborda que a luta pela sobrevivência ou interesse na manutenção da vida, encerra em si uma relação recíproca, em que matar outro ser vivo pode se tornar uma questão operacional natural de sobrevivência, com razão ou sem ela, e que estão inseridos nesses interesses os valores de uso naturais e/ou humanos.

A valorização do bem inerente de Paul Taylor e Tom Regan parece se basear nos princípios de igualdade e universalidade postulados por Kant, valores que parecem adequados a sistemas naturais isolados. O bem inerente é de uma grandeza incomensurável, pois o princípio da vida como valoração é estendido a todos os seres vivos. A valoração de Kenneth Goodpaster, baseada no conceito utilitarista de beneficência e não-maleficência, aponta para uma ampliação da possibilidade de diferenciação e priorização valorativa por parte de um julgamento moral do agente da ação. De qualquer forma, colocar-se no lugar do paciente moral, como outra vida natural, é essencial para o debate ampliado do respeito moral a todos os seres vivos.

Independente da questão valorativa relacionada à própria vida, se inerente ou intrínseca, a considerabilidade que o agente moral deve se esforçar em ter sob um ponto de vista biocêntrico, não pode partir somente das necessidades e anseios humanos, mas do ponto de vista do paciente moral, sua beneficência ou nãomaleficência, no respeito pelo interesse em viver ou na manutenção da vida. Assim, a questão da ampliação da considerabilidade moral passa, necessariamente, pelo próprio ser humano, pela construção de um novo pensamento moral que possa estar em consonância com a construção de uma nova humanidade: uma considerabilidade moral centrada na vida, quando a vida é essencial à própria condição humana.

Imaginar o ser humano e a transcendência humana na sua relação com a natureza no mundo moderno, não condiz com um pensamento do homem individualizado, sem considerá-lo enquanto instância humano-social. Ao mesmo R. Inter. Interdisc. INTERthesis, Florianópolis, v.11, n.1, p. 213-230, Jan./Jun. 2014 
tempo, não pode negar as novas relações que o ser humano estabelece com a natureza e as transformações advindas dela, sob uma perspectiva positiva do ser humano como agente moral e o meio ambiente vivo, como paciente moral. Uma comunidade ecológica e o seu meio, vistos como um todo dialético, em que diferentes níveis de existência são ontologicamente significativos, não possibilita um debate biocêntrico analisando-se de forma fragmentada as partes. Pois, o todo deve trazer consigo uma perspectiva transicional, em que o nascer e o morrer fazem parte desta luta natural e humano-transcendental pela existência.

Com sentido transformação da relação do ser humano com a natureza, considerando todos os seres vivos moralmente, criando novos critérios para além do humanismo e da senciência, esse humano que inexoravelmente se transforma socialmente, deve usar sua razão para elevar-se individual e coletivamente. Neste sentido, o trabalho como produto da relação do homem com a natureza adquire esse caráter social e processual histórico, e está presente nesse debate biocentrado. Desta forma, a proposta de igualdade e universalização pautadas pela ética biocêntrica passa, também, pela modificação de relações alienantes no trabalho e atomizadas na vida e nas relações entre humanos, como possibilidade de superação coletivo/social a uma liberdade e autonomia reais do agente moral, não de dominação de si próprio enquanto espécie da natureza ou seres de outras espécies, sencientes e não-sencientes.

Para que os seres humanos possam se situar além do humanismo, transformações no padrão societário ocidental moderno, baseado grandemente em interesses hedonistas, devem andar de mãos dadas com a luta pela preservação do meio ambiente e de respeito pela natureza. Construir esse novo agente moral é construir uma nova vida social que englobe de forma igualitária (em direitos) e universal (em valores) todo o ser vivo, em que o bem que é a vida esteja no centro do pensamento filosófico e nas atitudes deste agente moral.

R. Inter. Interdisc. INTERthesis, Florianópolis, v.11, n.1, p. 213-230, Jan./Jun. 2014
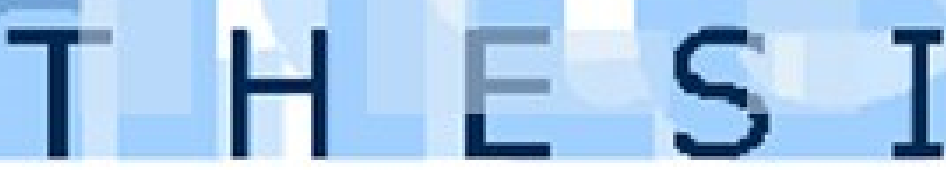


\title{
ENVIRONMENTAL ETHICS: NATURE AS A VITAL MOVEMENT
}

\begin{abstract}
A selection of articles from the contemporary environmental bioethics produced some questions and debates on the biocentric ethics. Two axes of analysis are developed: the first one shows the relationship between the moral agent and patient with the universalization of moral maxims, including all living beings, rational and non-rational, in moral considerability. The living beings are inter-related and need one another, but only humans are capable of moral judgments and, therefore, can be considered as moral agents, although it should be considered as moral from the patient's point of view. The second axis deals with the interest in maintaining life, which encompasses this reciprocal relationship, where killing another living being can become an operational issue of natural survival, whether right or wrong, and the natural and human values are inserted into these concerns. We conclude that the struggle to preserve the environment and respect for nature must go hand in hand with the possibility of the social emancipation of mankind. The construction of a new moral agent also involves construction of a new social life, which is where the benefit is - at the center of the philosophical thinking and attitudes of the moral agent.
\end{abstract}

Keywords: Ethics. Biocentric ethics. Bioethics environmental. Moral agent. Moral Considerability.

\section{UNA ÉTICA AMBIENTAL: A PARTIR DE LA NATURALEZA COMO UN MOVIMIENTO VITAL}

\section{Resumen}

Una selección de artículos de bioética ambiental contemporánea produjo algunas preguntas y debates sobre la ética biocéntrica. Se desarrollan dos ejes de análisis: el primero que muestra la relación entre el agente moral y el paciente, con la universalización de las máximas morales, incluyendo todos los seres vivos, racionales y no racionales, como moralmente considerables. Los seres vivos son inter-relacionados y precisan uno del otro, pero solamente los seres humanos son capaces de juicios morales y, por lo tanto, pueden ser considerados como agentes morales, aunque él debe ser considerado moral desde el punto de vista del paciente. El segundo eje aborda el interés en la conservación de la vida, que engloba esta relación de reciprocidad, en la que matar otro ser vivo puede tornarse un problema operacional de sobrevivencia natural, sea correcto o equivocado, y los valores naturales y humanos son incluidos en estas preocupaciones. Podemos concluir que la lucha para preservar el ambiente y el respeto por la naturaleza deben caminar de la mano con la posibilidad de emancipación social de la humanidad. La construcción de un nuevo agente moral también envuelve la construcción de una nueva vida social, que es donde está el beneficio - en el centro del pensamiento filosófico y en las actitudes del agente moral.

Palabras clave: Ética. Ética biocéntrica. Bioética ambiental. Considerabilidad moral. Agente moral.

R. Inter. Interdisc. INTERthesis, Florianópolis, v.11, n.1, p. 213-230, Jan./Jun. 2014 


\section{REFERÊNCIAS}

GOODPASTER, K. E. On Stopping at Everything: A reply to W. M. Hunt.

Environmental Ethics, University of North Texas, v. 2, n. 3, p. $281-284$, Spring. 1980.

GOODPASTER, K. E. On Being Morally Considerable. In: ZIMMERMAN, M. E. et al. Environmental Philosophy, New Jersey: Prentice Hall, 1998. p. 56 - 70.

REGAN, T. The Nature and Possibility of an Environmental Ethic. Environmental Ethics, University of North Texas, v. 3, n. 1, p. 19 - 34, Spring. 1981.

TAYLOR, P. W. The Ethics of Respect for Nature. Environmental Philosophy, New Jersey, Prentice Hall, p. 71 - 86. 1998.

HUNT, W. M. Are Mere Things Morally Considerable? Environmental Ethics, University of North Texas, v. 2, n. 1, p. $59-65$, Spring. 1980.

\section{Artigo:}

Recebido: Junho de 2013.

Aceito: Novembro de 2013.

R. Inter. Interdisc. INTERthesis, Florianópolis, v.11, n.1, p. 213-230, Jan./Jun. 2014 